\title{
The quality of public transport as a determinant of the number of car commuters
}

\author{
K. Karu, T. Rõivas, D. Antov, T. Oja \& Ü. Mander \\ Institute of Geography, University of Tartu, Estonia
}

\begin{abstract}
This paper examines residents' attitudes towards the quality of existing public transport, based on travel mode usage for job-based journeys. The hypothesis tested was that one of the important factors for car usage is a lower evaluation of the quality of public transport services by car users compared to users of alternative means of transport. The case study is based on data gathered from a survey performed in the city of Pärnu, Estonia. The Chi Square test $(\alpha=0.05)$ was used to determine socio-demographic differences between different mode user groups. Mean values of nondiscrete parameters were compared using the t-test. We grouped the statements about public transport quality based on the results of factor analysis and checked them against differences between different groups using the correlation analysis. Quality aspects considered for public transport quality evaluation were: public transport reliability, security, frequency, times of operation, schedule and routes, public transport cost as well as the preference of car usage or walking. The results of the analysis show that overall satisfaction with the quality of the public transport service was high or very high. The opinion of the car user group correlated highly only with preference of car usage. Thus the hypothesis was confirmed partly as car users prefer this mode of transport because of its higher comfort, and they also value the greater independence that a private car can give. The results confirmed the findings of many previous studies investigating the reasons for car usage, although some studies have also pointed out critical attitudes towards the reliability and connection speed of public transport.

Keywords: mode choice, travel behaviour, public transport quality, transport planning.
\end{abstract}




\section{Introduction}

Until the beginning of the 1990s, motorization levels in new EU Member States, including Estonia, were relatively modest compared to developed Western European countries (87 cars per 1000 persons in Estonia, 1980), due to restricted access to car ownership. The fall of the Soviet regime marked not only regained independence in the political arena, but also freedom of choice in the transportation sector. This led to a rapid increase in car ownership and usage, although the existing infrastructure was not designed for intensive traffic volumes. Although they have the possibility to avoid the mistakes made by countries that witnessed the massive incursion of car culture decades earlier, local officials in Estonia still try to adjust space to the needs of motor vehicles. The decrease in public transport usage, growing inequalities between users of different means of transport, health problems, growing traffic accident rates and other negative impacts of prevailing private motorized transport make decision makers at different administrative levels increasingly search for ways to reduce the demand for private cars. Changes always require one to understand the current situation and its impacts. Unfortunately, travel behaviour studies of local citizens are not very advanced in Estonia, and thus there is a huge field in the hands of transport researchers.

One of the main aims of this paper is to contribute to raising awareness about the travel behaviour of car commuters in Estonia. Our tested hypothesis is that one of the main factors influencing commuters' car usage is the lower evaluation of the quality of public transport services compared to users of alternative transport modes.

\section{Choosing car or public transport?}

Gardner and Abraham [7] stated that in order to effectively change travel behaviour, we need to determine the key beliefs and attitudes that influence the mode choice in the context of available alternatives. This assumption is based on the theory of planned behaviour, which predicts that behaviour is causally preceded by the relevant behavioural intention, and that intention is determined by attitudes and beliefs regarding the behaviour [6]. Public transport could be the most viable alternative for car commuters, and improving service quality on the basis of the expectations of current car users could help to regain some of the city space lost during the struggle against growing motorization. What, therefore, have been the main findings of earlier research in the field of the real reasons for car use?

In a broader sense, two categories of driving motivation have been revealed: instrumental or utilitarian motives and affective motives. The former represent the desire to maximize the expected utility of available transport modes in the context of current goals (e.g. costs, flexibility, predictability, travel time).

Affective motives express feelings evoked by the usage of the means of transport, such as stress, excitement, pleasure, boredom and control. Although many researchers have investigated utilitarian and affective motives separately, it is obvious that one affects the other [7,11]. For example, frequency of service 
has a direct impact on flexibility and interchange easiness, which also determines the way we feel about the convenience of using one or other means of transport. Collins and Chambers [3] have stressed the need to consider situational factors (e.g. car ownership, the availability of public transport services), as they form the framework in which current driving decisions are made. The latter is also supported by the empirical work of Kingham et al [10], showing that in a company in which $50 \%$ of employees have a company car and there are nonexistent public transport services and poor facilities for pedestrians and cyclists, $97.5 \%$ of workers travelled to work by car.

In investigating the preferences of car users, researchers have found that car owners unfortunately seem to praise the merits of their vehicles, which they mainly dislike in public transport $[5,7,8]$ or they simply rate car higher than public transport in the most important aspects [1, 4]. The latter could be explained by the findings of Ellaway et al [5], that regular users of a particular mode are more likely than non-habitual users to be positive about it. Analysing interviews according to grounded theory, Gardner and Abraham [7] extracted five overarching categories which represented motives for car use: journey time concerns and journey-based effect, minimising effort, personal space concerns, minimising monetary costs and a desire for control. Car use was commonly seen as having a positive effect on all of the aforementioned categories, while at the same time public transport was perceived as being relatively slow, boring, unreliable, uncontrollable, unattractive, requiring effort, and at best leaving one feeling indifferent and evoking feelings of vulnerability. Positive things such as the valuable usage of travel time or the potential health benefits gained by walking to a bus station were seldom mentioned. Thus car users tended to idealize their transport mode.

Flexibility, convenience, cost and predictability were seen as most important aspects for car commuters when Kingham et al [10] investigated conditions encouraging the usage of public transport for commuter journeys. Service frequency, flexibility and reliability are also three major aspects that could influence the feeling of control by reducing the uncertainties often related to public transport. This might also have a visible effect on public transport usage, as control over journey initiation and progression and a desire for control have, based on previous studies $[1,5,8,13]$, appeared to be very important to car users. Gardner and Abraham [7] found that retaining control underpinned most other motives, as it was seen to override other concerns such as journey time.

Nevertheless, travel time and cost have been almost conventional variables explaining travel mode choice $[1,13]$. Time is especially important in the case of functional trips, as it is related to certain obligations and appointments [8]. Van Vugt et al [13] came to the conclusion that the preference of public transport by those who commute to work everyday was not only determined by shorter average travel times but also by the belief that public transport is at least as reliable as private cars (variability in travel time is less or the same as in the case of private cars). Therefore the travel time argument could be quite closely connected to reliability and predictability, and in some cases to cost, as time spent on waiting for transport could mean a lost opportunity. Although real and 
perceived travel costs are important factors for everyday commuters [2, 3, 7, 10], as they might considerably affect household income, it is common that car users do not actually know or consider the real costs of car use. For example, the cost of a single car journey is converted solely in terms of fuel [7], which sets public transport at an unfair disadvantage, as it has been proven that those who believe public transport costs to be cheaper have higher ratings for public transport [3].

As mentioned above, car usage also provides positive emotions such as feelings of physical and social protection and satisfaction [9], but also personal safety, privacy, independence, prestige, higher self-esteem and mastery [5].

The importance of environmental considerations is open to discussion, as there have been contradicting findings. Gardner and Abraham [7] found no trace of relevance of environmental issues to car users, but according to the findings of Collins and Chambers [3], transport mode preference is primarily driven by egoistic beliefs, i.e. what is believed to have an effect on myself rather than others. Thus it could be the case that respondents simply did not feel that they could suffer from their environment-hostile behaviour, and it is actually a question of raising awareness and a feeling of personal responsibility. This is also supported by Van Vugt et al [13], who argues that people who rated highly factors concerning their personal welfare (comfort, flexibility, travel time, protection against weather) tended to commute to work by car, while people with greater concern for collective benefit had stronger preferences for public transport.

\subsection{Study area}

In terms of population (42,172 inhabitants), the city of Pärnu $\left(32.2 \mathrm{~km}^{2}\right)$ is the fifth largest city in Estonia and the most famous summer sea resort. It has nine districts: Kesklinn, the central area; Eeslinn, Rääma, Ülejõe and Rannarajoon, which form a circle around it; and Vana-Pärnu, Raeküla, Mai and Papiniidu, which are further from the centre. Two districts located in the fringe area Vana-Pärnu and Raeküla - are predominately single-family housing areas. In both the central area (Kesklinn) and Eeslinn, the predominant building types are small apartment buildings, but in Eeslinn there are also quite a lot of singlefamily homes. Rannarajoon has maintained its historical structure, so there are many villas and sanatoriums from various decades. The Ülejõe, Rääma, Mai and Papiniidu districts are the most populated areas, having many apartment buildings.

Despite the rapid development of the urban area, service levels of public transport have not managed to keep up with this trend, and at the moment provide no considerable competition to private cars. Traffic is rising steadily every year, as annual usage of private cars has increased over $10 \%$ during the last five years. Agreeing with Stradling et al [12], it is most likely the flexibility of the car that has encouraged additional journeys to further destinations. One of the significant contributors to the rise in car usage has been travel to work. Nevertheless, due to the regular nature of such trips, there is a relatively high potential to travel using alternative modes than in the case of less routine journeys [10]. 


\section{Data and methods}

The data for this study come from a 20-page face-to-face survey containing questions about transport mode preferences, as well as attitudes towards the quality of public transport. Background information about socio-economic conditions, demographics (i.e. gender, income level, age, marital status, family structure), living conditions and workplace were obtained as well. The sample was formed on the basis of the proportional distribution of citizens aged from 15 to 74 in the districts. A total of 500 citizens were interviewed, and the results were weighted to improve the estimates and expand the results to the whole population of the city aged between 15 and 74 .

From the viewpoint of this survey, respondents who had an occupation mattered, and therefore we included only those questionnaires in which both workplace and the means of transport usually used to get to work were stated. As we had information about travel to work in summer and winter, we used the difference test between the two proportions. The p-level was computed based on the t-value for the respective comparison. We found only one statistically significant difference $(p<0.0001)$, and that holds for bicycle users. Thus, considering the aims of the current study, there is no considerable relevance as to which dataset we use, as the main emphasis is on car users. Due to the fact that in the case of summer there were slightly more respondents and less car users, we chose these data as the basis for determining the mode users' profile. As a result of the applied weights, the total sample representing workers aged between 15 and 71 years of age was 277 respondents, of whom $44.7 \%$ were men.

For the data analysis we used statistical analysis software SPSS 10.0. The profile of users of different means of transport, especially car users, was determined through the Chi Square test $(\alpha=0.05)$, and its strength was measured by Cramer's V parameter. The results of the Chi Square test analysis will be given in brief, and only the main findings will be pointed out. Differences between the mean values of variables were compared using a t-test. The set of ratings to public transport quality was factor analysed using Principal Component Analysis with Varimax rotation. In order to determine differences between the satisfaction and dissatisfaction of users of means of transport towards developed factors, we conducted a correlation analysis. Car users who had never before used public transport were excluded from factor analysis so as to avoid possible biases.

\section{Results}

The current situation is that the majority of workers in Pärnu use private cars for regular travel to work, as shown in Fig. 1. A quarter of respondents go to work by foot, $23.8 \%$ use public transport, and almost ten percent used bicycles. Thus users of motorized modes represent over $2 / 3$ of the total commuters' modal split. In analysing the differences between the urban districts shown in Table 1, the main disparities were between the central district (Kesklinn) and Rääma. 
The Chi Square test confirmed significant relationships between gender, age, the presence of underage children in the household, educational level, income, evaluation of economic status, employment level, dwelling type, car availability and the means of transport used to travel to work. Car usage was more prevalent among men $(57.7 \%)$, whereas women preferred walking $(32.7 \%)$ or public transport $(30.7 \%)$ over car usage $(26.8 \%)$.

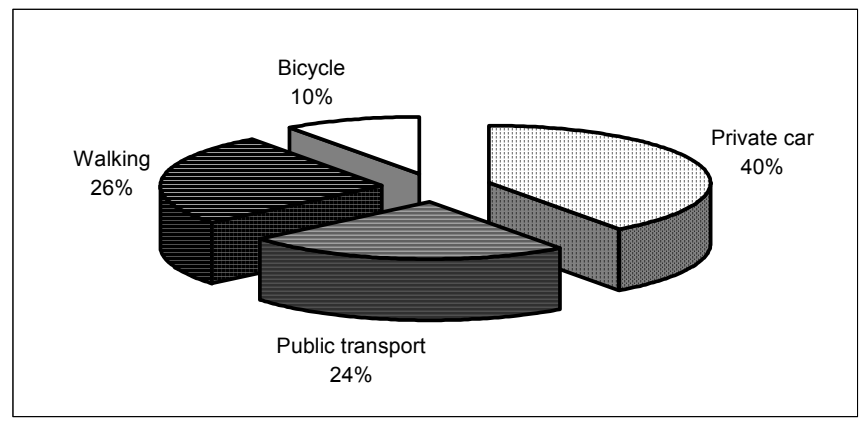

Figure 1: $\quad$ Modal split for commuter trips to work.

Table 1: $\quad$ Modal split of commuting in different districts.

\begin{tabular}{|l|r|r|r|r|}
\hline \multicolumn{1}{|c|}{ City district } & Walking (\%) & Bicycle (\%) & Private car (\%) & Public transport (\%) \\
\hline Kesklinn & 65.7 & 10.4 & & 23.9 \\
\hline Eeslinn & 35.5 & 10.0 & 35.6 & 18.9 \\
\hline Rääma & 14.5 & 8.3 & 52.4 & 24.8 \\
\hline Ülejõe & 31.3 & 16.5 & 23.6 & 28.6 \\
\hline Rannarajoon & 34.7 & & 42.9 & 22.4 \\
\hline Vana-Pärnu & 9.1 & 18.2 & 51.3 & 21.3 \\
\hline Raeküla & 9.5 & 10.4 & 53.7 & 26.4 \\
\hline Mai, Papiniidu & 31.9 & 5.7 & 40.9 & 21.5 \\
\hline
\end{tabular}

The relationship between age and the means of transport used was weak but still significant. The main conclusion was that car usage declined with age, whereas among the eldest age group (51 and over), public transport was the prevailing mode used to go to work. The average age of car users was lowest (38.6) and differed considerably from those who walked to work (42.8) or used public transport (44.3). Slightly over $50 \%$ of households with children were driving to work by car. The relationship between education and the means of transport used was difficult to explain based on Chi Square test results, as over $55 \%$ of highly educated persons and $36.9 \%$ of persons without higher education used a car to drive to work. Also better socio-economical conditions characterized car users, as car usage fell in connection with falling income levels. 
The population group with the lowest income mainly walked to work. Although the evaluation of households' social status is quite subjective, nevertheless, among those who rated their status as below average, car use was only $25.6 \%$, whereas among the highest-ranking group it was $65.4 \%$. Thus social status decreased with car use. Over half $(57.8 \%)$ of executive workers and specialists used cars to commute to work, but it was also most preferred by operators and craftsmen $(41.0 \%)$. Officials and workers in the service sector preferred public transport (32.1\%), and blue-collar workers mainly walked to work, as car users were the minority among them $(10.0 \%)$. Owners of single-family houses were predominantly $(56.3 \%)$ car users, $42.1 \%$ of inhabitants of small apartment buildings walked to work, and only $23.7 \%$ used cars. Residents of apartment buildings used cars (35.7\%) almost as much as public transport (31.8\%). Finally, among car users the average number of cars in the household was significantly higher (1.17) than among users of alternative modes (walkers 0.69 , bicyclers 0.70 , public transport users 0.35 ).

Next we investigated attitudes of car users towards different aspects of the quality of public transport. The overall evaluation of public transport services was good or very good, but the only factor causing dissatisfaction was the cost of public transport. There were also somewhat negative opinions of the operating hours of bus traffic, the frequency of service and the comfort of the vehicles. Nevertheless, over half of the respondents found these factors to be satisfactory or very satisfactory. Regardless of the good evaluation of current public transport services, over half preferred a car over it. Considering that the majority of trips to work are performed during peak hours, it is alarming to note that most respondents considered public transport to be overcrowded during rush hour. As many questions concerning the quality of public transport referred to similar aspects or were interrelated, we conducted factor analysis assuming that they would together provide a more reliable picture of some general latent phenomena than provided by an answer to a single question. In the end we concluded with a six-factor solution, leaving variables with communalities of under 0.3 out of the analysis. Those six factors explain altogether $57.9 \%$ of the total variability, $13.8 \%, 11.1 \%, 10.4 \%, 8.4 \%, 7.3 \%$ and $6.9 \%$ respectively. As shown in table 2, the values of Cronbach's alpha were between 0.65 and 0.86 .

Table 2: $\quad$ Results of factor analysis.

\begin{tabular}{|l|c|c|c|}
\hline \multicolumn{1}{|c|}{ Factor } & $\begin{array}{c}\text { Variable loading most highly } \\
\text { on factor }\end{array}$ & $\begin{array}{c}\text { Number of variables loading } \\
\text { on factor }\end{array}$ & Cronbach's alpha $(\alpha)$ \\
\hline $\begin{array}{l}\text { F1- Reliability and safety (location } \\
\text { based) }\end{array}$ & $\begin{array}{c}\text { Dissatisfied with the } \\
\text { reliability of PT services }\end{array}$ & 7 & 0.78 \\
\hline $\begin{array}{l}\text { F2 - Frequency and operating } \\
\text { hours }\end{array}$ & PT services end too early & 5 & 0.76 \\
\hline F3- Schedule and routing & $\begin{array}{c}\text { I must change buses to get } \\
\text { to work }\end{array}$ & 6 & 0.73 \\
\hline F4- Preference for cars & I prefer to use a car & 4 & 0.65 \\
\hline F5- Preference for walking & $\begin{array}{c}\text { Everything I need is within } \\
\text { walking distance }\end{array}$ & 3 & 0.66 \\
\hline F6- PT costs & Tickets are expensive & 2 & 0.86 \\
\hline
\end{tabular}


The first factor was dissatisfaction with the reliability and safety of public transport. People who agreed with this factor considered that public transport is not reliable and punctual, and it makes you feel unsafe. In addition, one locationbased statement loaded on this factor: dissatisfaction with the connection to the city centre. Only those living in small apartment buildings in the beach district (Rannarajoon) correlated positively with this factor. It may be due to the bad connection that many inhabitants of that particular district felt a barrier to use public transport, and currently use alternative means of transport.

A second factor could be described as dissatisfaction with the frequency and operating hours of bus services. Respondents were not satisfied with the operating hours and believed that buses did not go frequently enough, and unsuitable departure times were also mentioned. This factor correlated with the sex of the respondent, as it was mostly women who agreed with it. This could be due to the division of labour in the family, as it is most often for women to have multiple tasks after work before they arrive home. Thus having a frequent service is very important to guarantee their smooth travel, as public transport users together with walkers form a large proportion of them.

A third derived factor was dissatisfaction with the schedule and routes. This embraced statements like: public transport schedules and/or departure times and routes are unsuitable for me. Often the person's destinations lack a public transport connection. Once again the factor is correlated only with residential district and dwelling type. In this case it was not persons not living in the Rääma district and apartment buildings but instead inhabitants of small apartment buildings who held that view.

Preference for car usage was the fourth factor, and included statements like 'I prefer to use a car', 'I have multiple trips during a day that are just more comfortable to do by car'. Also, dissatisfaction with the comfort of public transport vehicles and overcrowding underlay this factor. As expected, this factor was positively correlated to everyday car users and not walkers or public transport users, more likely younger persons with higher than average social status, and not blue-collar workers. This was the only factor where having a car was important, as a car was preferred by those who had access to at least one car.

A fifth factor was the preference for walking. As previously, the factor was positively correlated to the means used to travel to work, in this case walkers who do not use public transport on an everyday basis. We also found a positive relationship between users of non-motorized means of transport.

The final factor was the cost of travel and related dissatisfaction with public transport ticket prices, considering them to be too high. Although one may expect that this factor would be correlated with income or social status, the variables actually related were age, residential district (central district Kesklinn) and dwelling type. As inhabitants of the central district were relatively young and there were no respondents from this district who would have lived in singlefamily houses, we could assume that the problem is instead district-specific. Keeping in mind our study objective, the most important fact is that the majority of residents were walking to work. 


\section{Discussion}

Understanding the factors that influence commuters-transport choice is important for the development of effective strategies for a commuting mode shift in a sustainable direction [3]. In our case we tried to understand the influence of public transport quality on car commuting. Overall, the service quality was quite highly rated, and the only concerning aspects related to everyday work trips were dissatisfaction with high ticket prices and overcrowded buses. As cost and travel convenience are very important factors for commuter trips, this is one area where officials and operators must cooperate to achieve effective solutions such as more frequent service and discounts for regular customers. Another incentive to use public transport more frequently could be provided by employers, by compensating tickets to work, as car users are usually provided free parking.

In trying to derive certain quality aspects that should be changed in the viewpoint of car commuters, we found that many car users simply consider driving to be more pleasant, which is due to the more comfortable travelling and flexibility provided by a private motor vehicle. Preferring a car due to its comfort has been mentioned in several previous studies in which commuting to work was investigated. The importance of flexibility as a separate factor has occurred less often, but in a study by Anable and Gatersleben [1], these two were the most highly rated qualities of a car for car users, when compared to its alternatives. Nevertheless, we found no relation towards stronger consideration of travel time or requiring more reliable service by car commuters, as in some earlier papers, and therefore our hypothesis was only partly confirmed, since in addition to these two arguments (flexibility and comfort), car users were not more negative towards other characteristics of public transport.

Certainly the results are not comprehensive enough to make conclusive decisions about what needs to be changed in the public transport system, as the questions analysed were limited. Nevertheless, we find that our study provides insight into possible motives and arguments for the behaviour of everyday car commuters, which is a good basis for further research. We admit that the results may be influenced by the fact that those who had never used public transport were excluded from factor analysis. It would be very useful to concentrate on this commuter group in order to determine possible biases and misconceptions among habitual car users that keep them from switching to public transport.

There is also another aspect that needs further investigation in order to develop strategies addressed to changing travel behaviour. Knowledge of the changes that are needed is not enough, as we must also identify the potential for mode switches by investigating the willingness to shift commuter transport mode. Kingham et al [10] came to the conclusion that car sharing would be a measure with the highest potential to influence the number of cars on the road, as people seem to be attracted by the thought of continuing to use a car, while at the same time helping to reduce congestion. It would be interesting to know how responsive Estonian car commuters are to the various measures that have been applied elsewhere in order to change travel behaviour. The aims of sustainable 
transport policies are challenging but worth fighting for, as we all wish to breathe cleaner air, have safer streets and more freedom to choose our destinations.

\section{References}

[1] Anable, J. \& Gatersleben, B., All work and no play? The role of instrumental and affective factors in work and leisure journeys by different travel modes. Transportation Research Part A, 39, pp. 163-181, 2005.

[2] Bamberg, S., Ajzen, I. \& Schmidt, P., Choice of Travel Mode in the Theory of Planned Behavior: The Roles of Past Behavior, Habit, and Reasoned Action. Basic and Applied Social Psychology, 25(3), pp. 175$187,2003$.

[3] Collins, C. M. \& Chambers, S. M., Psychological and situational influences on commuter-transport-mode choice. Environment and Behaviour, 37, pp. 640-661, 2005.

[4] De Palma, A. \& Rochat, D., Understanding individual travel decisions: results from a commuters survey in Geneva. Transportation, 26, pp. 263281, 1999.

[5] Ellaway, A., Macintyre, S., Hiscock, R. \& Kearns, A., In the driving seat: psychosocial benefits from private motor vehicle transport compared to public transport. Transportation Research Part F, 6, pp. 217-231, 2003.

[6] Fishbein, M. \& Ajzen, I., Belief, Attitude, Intention, and Behavior: An introduction to Theory and Research, Addisson-Wesley: Reading, Massachusetts, pp. 335-383, 1975.

[7] Gardner, B. \& Abraham, C., What drives car use? A ground theory analysis of commuters' reasons for driving. Transportation Research Part $F, 10$, pp. 187-200, 2007.

[8] Hine, J. \& Scott, J., Seamless, accessible travel: users' views of the public transport journeys and interchange. Transport Policy, 7, pp. 217-226, 2000 .

[9] Hiscock, R., Macintyre, S., Kearns, A. \& Ellaway, A., Means of transport and ontological security: Do cars provide psycho-social benefits to their users? Transportation Research Part D, 7, pp. 119-135, 2002.

[10] Kingham, S., Dickinson, J. \& Copsey, S., Travelling to work: will people move out of their cars. Transport Policy, 8, pp. 151-160, 2001.

[11] Steg, L., Vlek, C. \& Slotegraaf, G., Instrumental-reasoned and symbolicaffective motives for using a motor car. Transportation Research Part F, 4, pp. 151-169, 2001.

[12] Stradling, S. G., Meadows, M. L. \& Beatty, S., Helping drivers out of their cars. Integrating transport policy and social psychology for sustainable change. Transport Policy, 7, pp. 207-215, 2000.

[13] Van Vugt, M., Van Lange, P. A. M. \& Meertens, R. M., Commuting by car or public transportation? A social dilemma analysis of travel mode judgements. European Journal of Social Psychology, 26, pp. 373-395, 1996. 